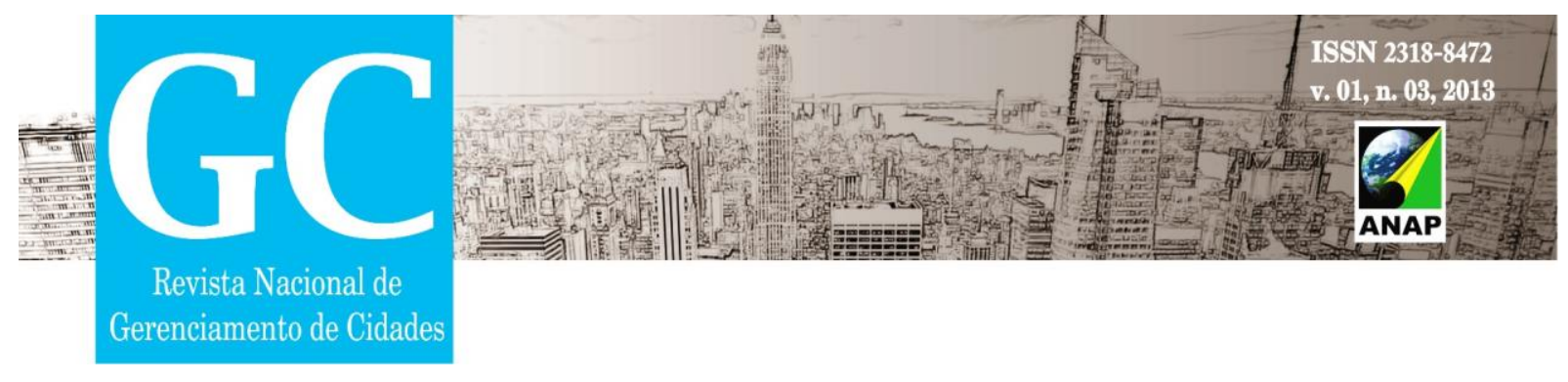

\title{
IMPACTOS SOCIOAMBIENTAIS DECORRENTES DAS ATIVIDADES TURÍSTICAS NO MUNICÍPIO DE RIO QUENTE (GO)
}

\author{
Roberta Vieira de Oliveira Ramos ${ }^{1}$
}

Idelvone Mendes Ferreira ${ }^{2}$

Resumo: $\mathrm{Na}$ atualidade, no processo de desenvolvimento das atividades socioeconômicas, o setor do turismo é um dos que mais tem crescido nos últimos anos e está ligado diretamente às questões ambientais e sociais, sendo capaz de expor nosso patrimônio natural e cultural, onde a natureza é vista como sendo um produto a ser vendido. O presente estudo visa analisar os impactos socioambientais e econômicos decorrentes das atividades do turismo nas estâncias termais e suas percussões no desenvolvimento local e regional, enfocando os elementos que caracterizam um turismo planejado. As ações decorrentes dessas atividades turísticas têm causados impactos ambientais e sociais, tanto negativos quanto positivos, para o município de Rio Quente (GO) e para a região, sendo o foco desta pesquisa a análise dos impactos socioambientais negativos, uma vez que são mais impactantes e perniciosos para a sociedade.

Palavras- chave: Turismo. Impactos socioambientais. Rio Quente (GO).

\footnotetext{
1 Aluna do Programa de Pós-Graduação em Geografia, Campus Catalão/UFG. Núcleo de Estudos e Pesquisas Socioambientais/CNPq-CAC/UFG. E-mail: rvoramos160175@gmail.com

${ }^{2}$ Professor do Programa de Pós-Graduação em Geografia, Campus Catalão/UFG. Coordenador do Núcleo de Estudos e Pesquisas Socioambientais/CNPq-CAC/UFG. E-mail: idelvoneufg@gmail.com
} 


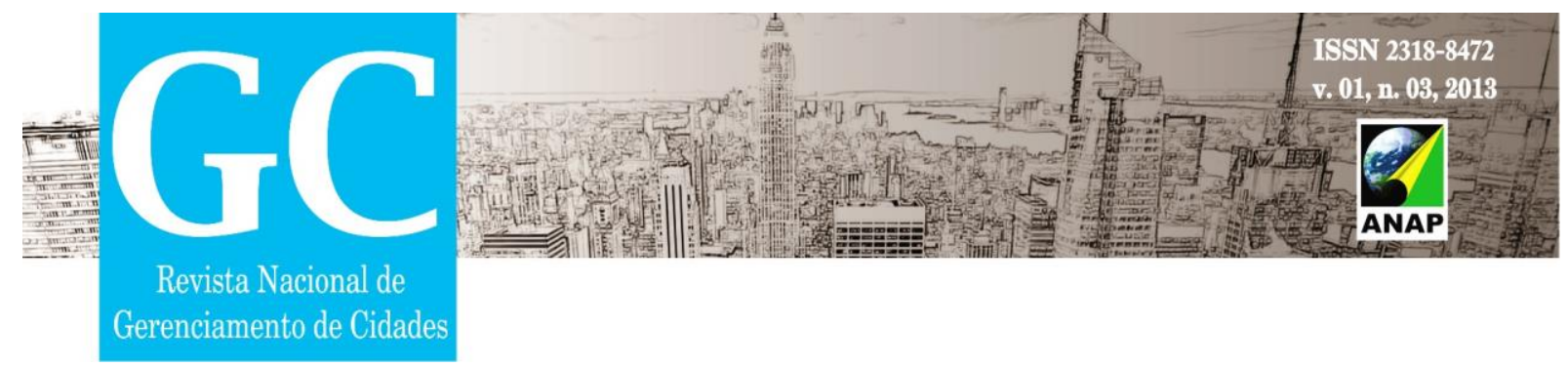

\section{INTRODUÇÃO}

Durante muito tempo o turismo foi considerado uma atividade econômica limpa, não poluente, constituindo-se numa das maiores falácias da sociedade. Porém, atualmente, é reconhecido como um causador de impactos, tanto positivos quanto negativos ao ambiente natural o que tem aumentado as preocupações de governantes, organizações não-governamentais e, principalmente, daqueles que possuem grande interesse econômico no turismo por ambientes naturais.

Com o final da Segunda Guerra Mundial (meados do século $X X$ ), o turismo expandiu-se e consolidou-se, surgindo o turismo de viagens econômicas com todos os serviços incluídos (pacotes turísticos), organizadas pelas agências e operadoras de viagens, principalmente nos países do chamado "Primeiro Mundo" em detrimento das condições adversas dos países menos desenvolvidos.

Após essa expansão, o turismo tomou novos rumos e as forças produtivas da sociedade alavancaram a procura pelo turismo em seus diferentes focos. Na mesma proporção aumentaram os investimentos financeiros na exploração natural e/ou cultural do ambiente, nas pesquisas profissionais e estudos acadêmicos voltados para o turismo 0 que tem despertado a atenção e a responsabilidade por parte de alguns gestores públicos e da própria sociedade.

Decorrente desse processo, os municípios brasileiros em seus diferentes contextos veem, em sua maioria, enfrentando inúmeros problemas em diversas áreas inerentes às questões socioambientais, como a falta de saneamento básico, a coleta precária de lixo, déficit na infraestrutura local e na saúde, entre outras atividades correlatas. Problemas estes que devem ser analisados de forma conjunta pelos setores público e privado.

Nesse cenário, especial ênfase é dada ao desenvolvimento sustentável do uso racional das águas, considerando um processo de transformação que ocorre em conjunto nas dimensões social, ambiental, cultural e econômica a partir do individual para o global. 


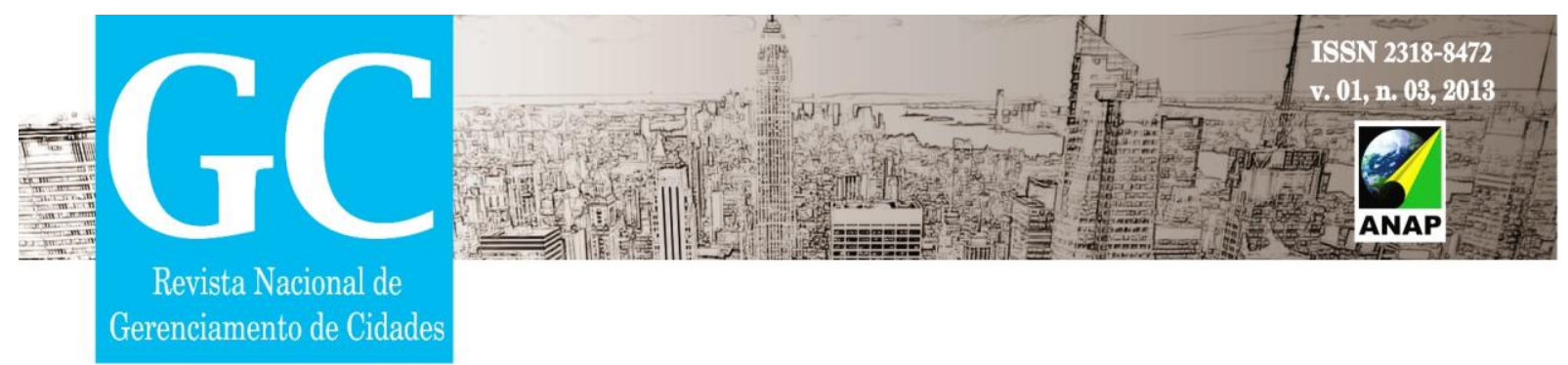

Essas dimensões estão ligadas por meio de instituições que se interagem, influenciando no comportamento da sociedade local.

Entender esse cenário de relações que se estabelecem em determinado lugar é tarefa primordial para a compreensão dos aspectos geográficos e também para a área do conhecimento do turismo. Nesse sentido, buscar-se-á uma forma de turismo em que a preservação da natureza, e o uso racional da água, estejam em combinação com o fluxo turístico.

\section{Caracterização da área de estudo}

Segundo dados do IBGE - Instituto Brasileiro de Geografia e Estatística (Censo 2010), o município de Rio Quente-GO está localizado no Centro-Oeste Brasileiro, na porção Sul do Estado de Goiás, na bacia do Rio Corumbá. Limita-se com os municípios de Água Limpa; Caldas Novas; Marzagão e Morrinhos.

O município de Rio Quente tem como atividade principal o turismo que possui uma vasta rede hoteleira influenciando diretamente na economia da região, na atração de turistas de lazer, negócios, esportes, religioso, entre outras atividades turísticas.

Essa influência no Município e na região das Águas Quentes está intimamente ligada ao uso das águas termais e cristalinas do Rio Quente, bem como do aquífero termal profundo, localizado no setor da Esplanada do Rio Quente, com seu pressuposto potencial terapêutico. O Município é beneficiado ainda com fauna e flora ricas e exuberantes, uma das mais belas serras de Goiás - Parque Estadual da Serra de Caldas Novas - PESCAN (Figura 2) com vegetação característica do Bioma do Cerrado. 

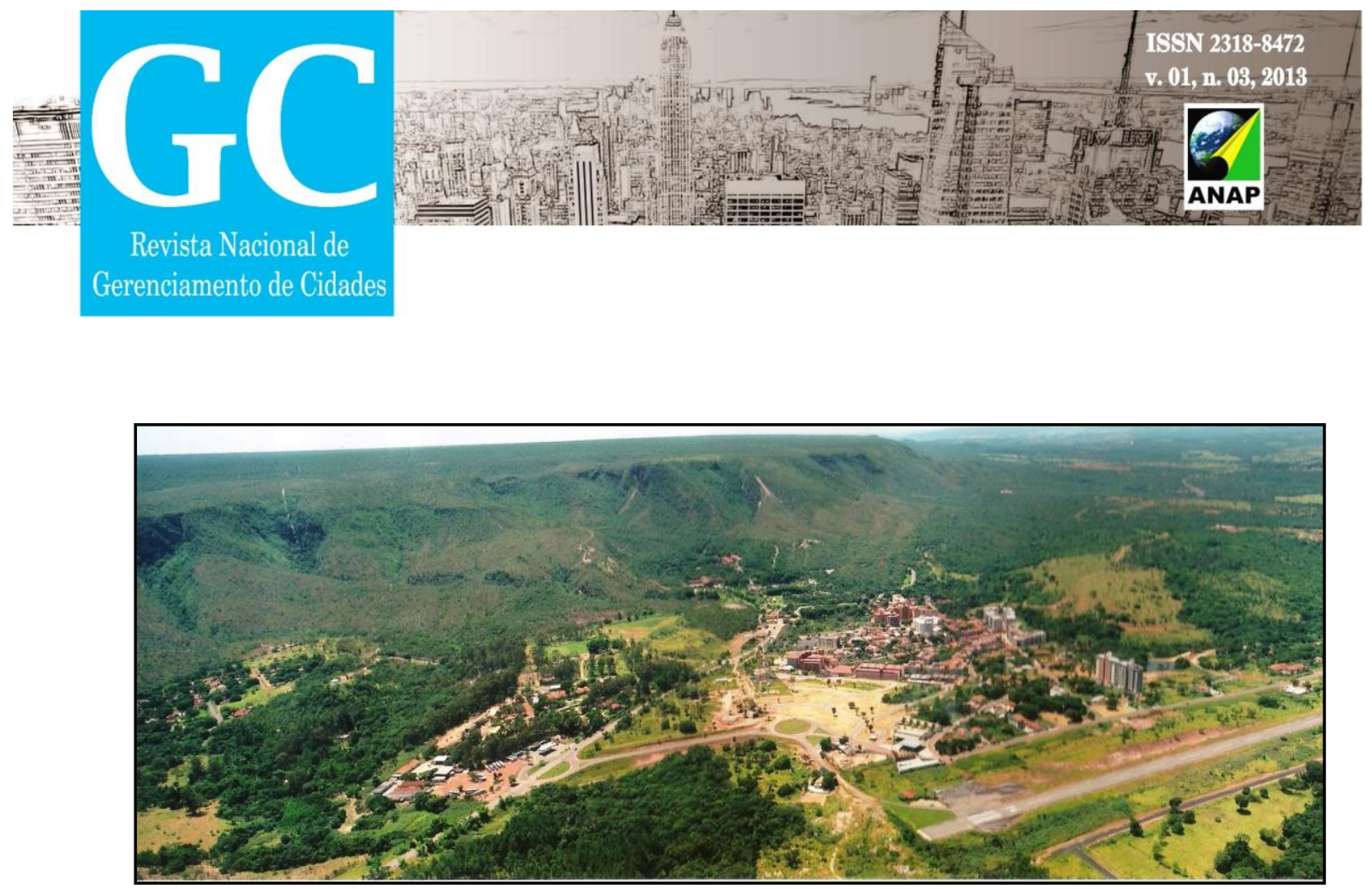

Fonte: OLIVEIRA, O. V. (2008)

Figura 2 - Setor Esplanada do Rio Quente, ao fundo a Serra de Caldas Novas em Rio Quente (GO)

\section{CONCEITUAÇÃO DE TURISMO}

O termo "turismo", hoje, possui significado na mente das pessoas que podem bem defini-lo por já terem, de alguma maneira, exercido essa atividade considerando-se, portanto, um turista. Contudo, ao longo dos anos evolui de acordo com a realidade e as mudanças socioeconômicas da população. Analisando as mudanças estruturais que facilitaram o desenvolvimento do turismo, podemos citar as construções e melhorias das estradas e aeroportos, proporcionando transporte de qualidade para o acesso aos pontos turísticos. Por isso, Bissoli (1992) define turismo como sendo:

[...] o conjunto de recursos capazes de satisfazer as aspirações mais diversas, que incitam o indivíduo a deslocar-se do seu universo cotidiano, e assim caracteriza-se por ser uma atividade essencialmente ligada à utilização do tempo livre. (BISSOLI, 1992, p. 121).

Nas diversas definições encontradas sobre o turismo, existem elementos que são citados como o deslocamento (distância percorrida) relativamente do lugar de residência, a duração da viagem e os seus motivos para a viagem, que para Ignarra (2003), o turismo 


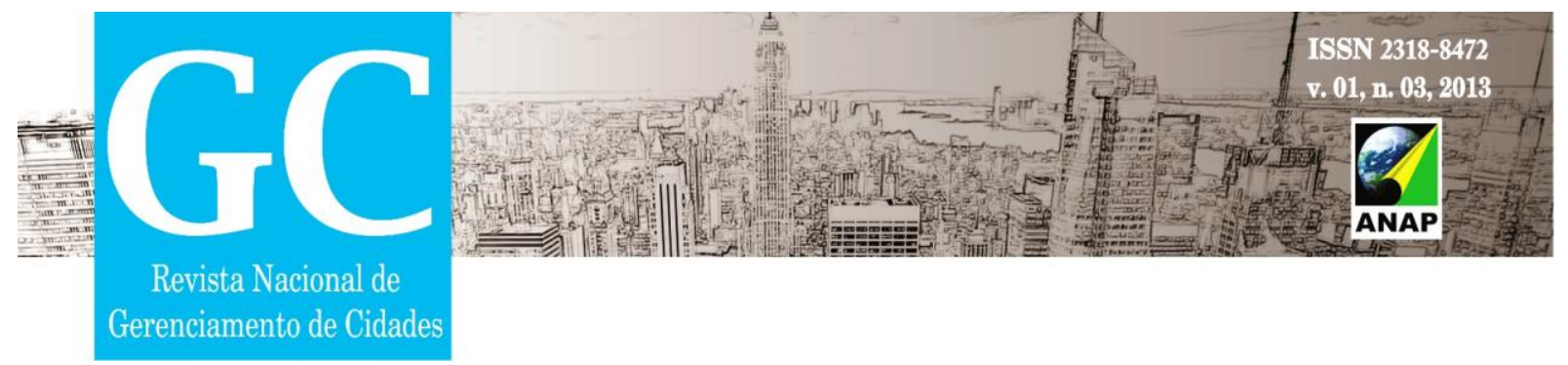

seria as viagens em que as pessoas permanecem fora de seu ambiente usual não mais do que um ano consecutivo, por negócio, lazer, prazer ou outros fins.

O turismo como forma de lazer, que organiza e planeja o tempo livre da sociedade atual (pelo menos é o que se espera), passa a exigir novos modelos de espaços correspondendo aos novos tipos de relações no nível humano contribuindo, assim, para a circulação de capital, melhoria econômica de uma região e do ambiente. Sendo assim, para Ignarra (2003) o turismo, como um aspecto econômico, é considerado:

[...] conjunto de viagens que tem por objetivo o prazer ou motivos comerciais, profissionais ou outros analógicos, durante os quais é temporária sua ausência da residência habitual [...] (IGNARRA, 2003, p. 12).

Essa definição é destacada pelos aspectos socioeconômicos da atividade turística, coincidindo com o deslocamento das pessoas de sua residência fixa, por uma temporada, para outro lugar. A atividade turística está ligada ao conjunto de serviços e indústrias relacionados ao transporte, alojamentos, alimentação e lojas entre outros contextos.

\section{Origem das águas termais}

Muitas teorias foram levantadas para saber como essas águas se formam e quais seus efeitos para a saúde. Segundo Saint-Hilaire et al (1982) quando começaram a propagar o prodígio das termas da região do Rio Quente, devido à falta de conhecimento da época, vez que a serra assemelha-se a um cone, diziam que a alta temperatura era devida a um vulcão extinto. Ao passar dos anos surgiram várias teorias sem comprovação científica como a do rio subterrâneo e a do aquecimento pelo urânio radioativo. Na atualidade, porém, a teoria mais aceita é a do aquecimento da água pelo calor da Terra.

Esse processo de aquecimento das águas começa quando a água das chuvas cai nas áreas de captação da Serra de Caldas e penetram nas fissuras das rochas, infiltrando-se em profundidade de cerca de 1500 metros, aquecendo-se progressivamente 


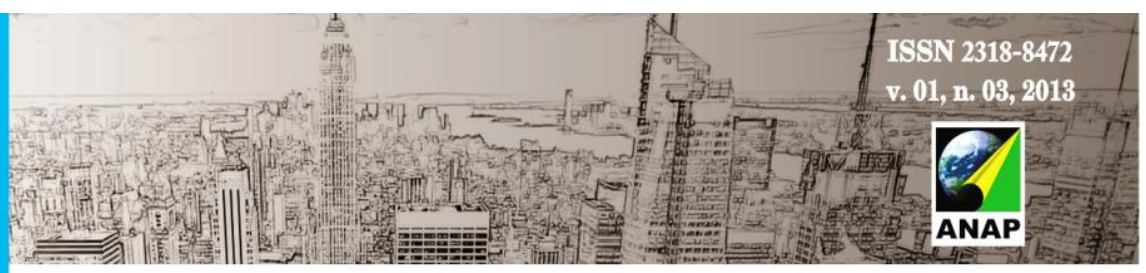

Revista Nacional de

Gerenciamento de Cidades

e chegando a mais de $70^{\circ} \mathrm{C}$ de temperatura pelo fenômeno denominado geotérmico ${ }^{3}$. Já aquecidas, adquirem pressão própria, iniciando o caminho de volta através de outras fissuras e misturando-se com águas da superfície, ainda sob pressão, procura partes mais baixas para brotar em grandes nascentes e dezenas de outras minúsculas formando o Rio Quente, todas localizadas no complexo Rio Quente Resorts a uma temperatura média de $37,5^{\circ} \mathrm{C}$.

\section{Impactos ambientais}

Segundo o Artigo 1ํ da Resolução n.ำ 001/1986, do Conselho Nacional do Meio Ambiente (CONAMA), Impacto Ambiental é:

[...] qualquer alteração das propriedades físicas, químicas, biológicas do meio ambiente, causada por qualquer forma de matéria ou energia resultante das atividades humanas que afetem diretamente ou indiretamente: a saúde, a segurança, e o bem estar da população; as atividades sociais e econômicas; a biota; as condições estéticas e sanitárias ambientais e a qualidade dos recursos ambientais (CONAMA, 1986).

Os impactos ambientais advindos do turismo surgem devido às modificações e transformações que essa atividade ocasiona no meio natural. Como aponta Ruschmann (1997) os impactos são resultados de um processo de interação complexo entre os turistas, as comunidades e os meios receptores e não de uma causa específica.

\footnotetext{
Para os estudos de impactos ambientais urbanos, é de relevante importância que sejam feitas análises das situações e de aspectos específicos, de forma isolada, a fim de obter resultados mais precisos. Posteriormente, é ideal que seja feito uma análise sobrepondo todas as informações adquiridas, de modo a contribuir positivamente para a recuperação da área e para prevenção de futuros problemas. (CUNHA, 2001, p. 51).
}

Com isso o meio ambiente vem sendo representado pela problemática ambiental, tornando-se cada vez mais importante para a reflexão que para Dias, ‘[...] não é somente

\footnotetext{
${ }^{3} \mathrm{O}$ gradiente geotérmico significa dizer, simplificando, que, aproximadamente a cada 33 metros, rumo ao interior da Terra, há um aquecimento de $1^{\circ} \mathrm{C}$.
} 


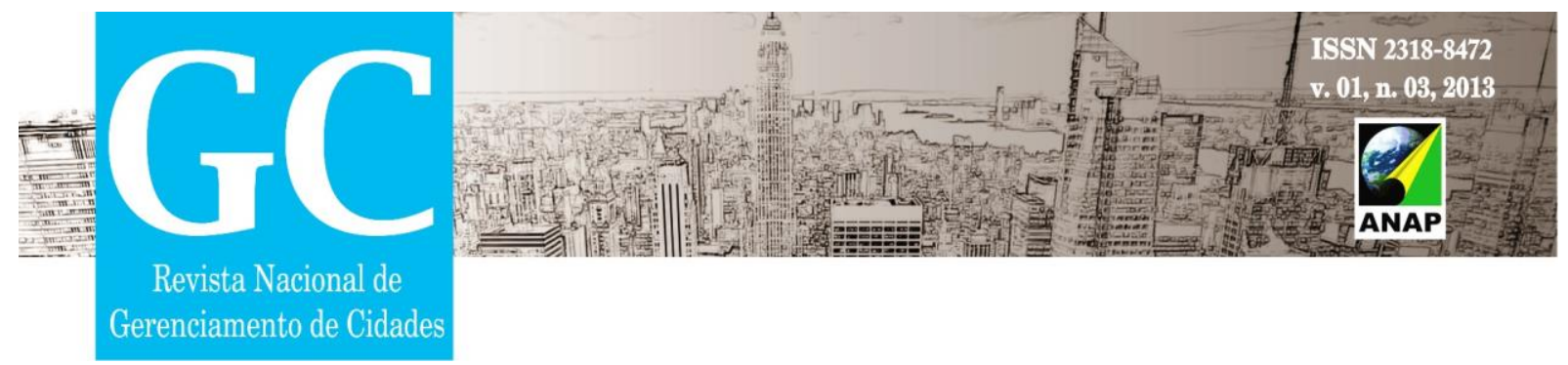

homem em si que prejudica o meio ambiente, mas também o que gera o crescimento do mesmo" (DIAS, 2000, p. 253).

Dentre os impactos positivos da atividade turística no meio natural, devemos destacar a criação de áreas, programas e entidades governamentais e não governamentais com a proteção da fauna e da flora. Dias (2003, p. 87), relata que: "[...] o turismo tem um potencial de criar efeitos benéficos no meio ambiente, contribuindo para a proteção ambiental e a conservação." Essa idéia pode ser o caminho para o crescimento da consciência ambiental, podendo servir como ferramenta para a proteção das áreas naturais.

Após o século XIX, para atrair o turista, a natureza foi manipulada e transformada em mercadoria, desse modo montanhas, praias e águas entraram no contexto da troca, como área de lazer, tornando uma atividade capitalista, exploratória, mudando seu significado, tornado um fator negativo para os recursos naturais, que segundo Becker (1996):

A natureza hoje muda de significado, neste contexto, deixa de ter significados antigos como dotação de recursos ou como base da reprodução e grupos nativos. Ela passa a ser capital. Capital de realização atual, ou de realização futura [...]

É o caso da biodiversidade, que pode servir de fonte para ciência e tecnologia e é o caso, também, da valorização da natureza como produto, como mercadoria para o turismo, também outro significado atribuído à natureza (BECKER,1996, p. 182).

Ainda, Dias (2003) descreve que há muitos aspectos negativos no turismo, que podem surgir no desenvolvimento da infraestrutura, no manejo incorreto do solo, na receptividade da quantidade de turistas, afetando a sociedade local e o ecossistema da região. Assim, Ruschmann (1997) aponta que:

[...] o impacto do turismo sobre o meio ambiente jamais será nulo, [...] as depredações dependem da vulnerabilidade do meio. A vulnerabilidade de um atrativo ou local turístico depende da fragilidade dos ecossistemas que compõem o meio e para preservar sua integridade, é preciso delimitar a "capacidade de carga" [...] que este pode suportar sem comprometer as características que originaram sua atratividade. (RUCHMANN, 1997, 48, grifo do autor).

Esses impactos negativos são acentuados quando vinculados à falta de planejamento. Dias $(2000$, p. 76 ) coloca que: "[...] o turismo, quando integrado a um 


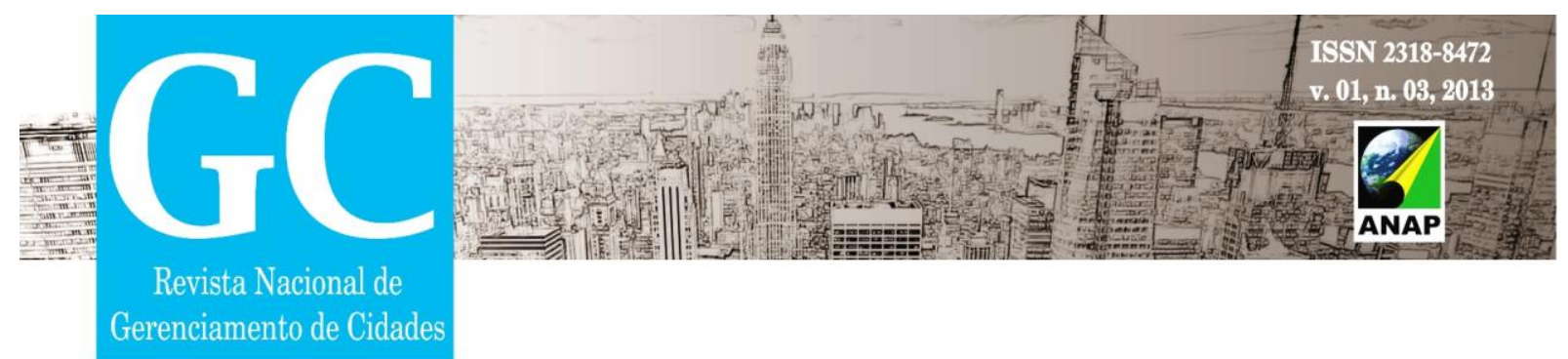

processo de planejamento desde seu início, pode produzir efeitos positivos no trato com o meio ambiente". O autor aponta que o desenvolvimento da atividade turística sem um planejamento adequado, envolvendo profissionais das mais diversas áreas, gera uma degradação no ambiente.

Os impactos ambientais, derivados da falta de planejamento, apresentam-se como a principal preocupação dos planejadores e gestores que buscam, através do turismo sustentável, o monitoramento, a assessoria e a administração desses impactos, desenvolvendo métodos confiáveis de obtenção de respostas e opondo-se a qualquer efeito negativo do turismo.

\section{CONCLUSÃO}

O crescimento do turismo não afeta apenas a economia local, mas também o ambiente natural, os aspectos físico e sociocultural dos municípios. Para o devido entendimento desse processo são fundamentais as reflexões e discussões sobre os impactos oriundos das atividades turísticas, apontando propostas para minimizar os impactos negativos e aperfeiçoar os impactos positivos.

Um turismo mal planejado e/ou uma gestão deficiente pode levar a efeitos negativos para a região, trazendo impactos ao ambiente de tipos e modos específicos como, prejuízos ao solo, poluição dos recursos hídricos, perda da biodiversidade, principalmente da flora e fauna, aumento da quantidade de lixo e outros impactos ambientais indiretos.

Dessa forma, há a necessidade de um planejamento eficiente das atividades turísticas para que realmente sejam alcançados resultados promissores e satisfatórios de qualidade socioambiental.

Segundo descreve Bertha Becker (1996):

[...] o turismo pode se transformar num vetor de desenvolvimento, capaz de realizar a passagem para um modo de produzir sustentável, saindo daquela ótica do desenvolvimento rápido a qualquer preço. E também ser um vetor de 


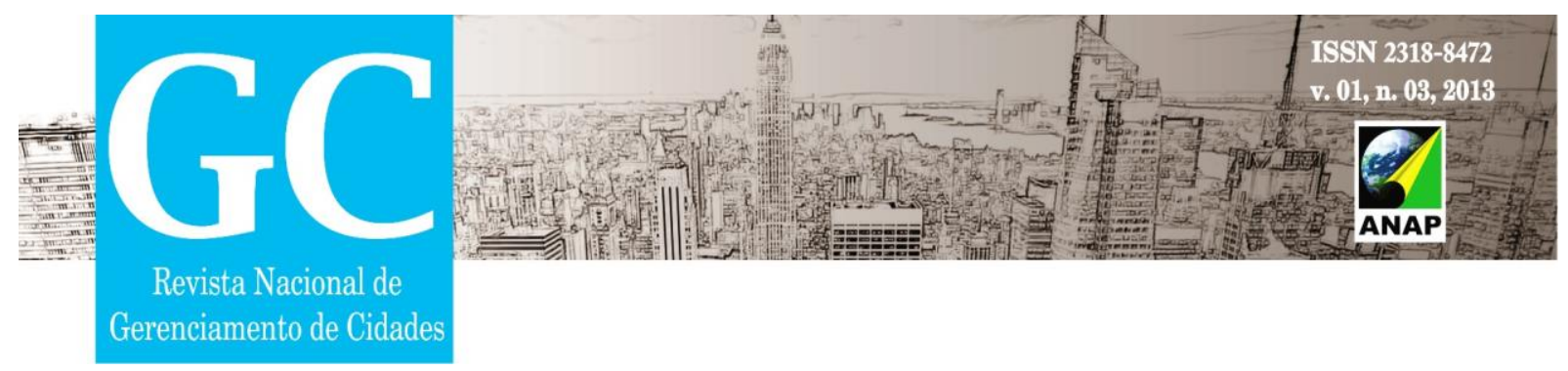

desenvolvimento dentro dos parâmetros do modo de produzir que considere a natureza; que poupa recursos (BECKER,1996, p. 186).

O grande desafio, hoje, para todos os atores sociais e pesquisadores envolvidos nas diferentes modalidades turísticas é o de transformar as pesquisas do turismo em estratégias sustentáveis, economicamente viáveis e ambientalmente corretas. É preciso identificar os impactos socioambientais gerados pelo turismo antes que os espaços natural e social sejam afetados nocivamente pelo homem de forma definitiva. Essas medidas farão com que o turismo seja aproveitado com maior responsabilidade, rentabilidade e menores prejuízos ao ambiente.

\section{REFERÊNCIAS}

BECKER. B. Políticas e planejamento do turismo no Brasil. In YÁZIGI. E., CARLOS. A. F. A., CRUZ. R. C. A. (Org) Turismo: Espaço, Paisagem e Cultura. São Paulo: Hucitec, 1996. 238p.

BISSOLI, M. A. A problemática econômica e social do espaço turístico. Revista Comunicarte, Campinas, IAC/PUCCAMP, v.16-17, p. 116-149, 1996. Disponível: < http://www.estantevirtual.com.br/q/instituto-de-artes-e-comunicacoes-puccampcomunicarte-16-17>. Acesso em: 10 de set. de 2013.

BRASIL, Conselho Nacional de Meio Ambiente. CONAMA. Resolução n.. 001/1986. Disponível:<http://www.mma.gov.br/port/conama/legi.cfm> Acesso em 07 de ago. 2013.

CUNHA, S. B. da; GUERRA, A. J. T. (Orgs.). Impactos Ambientais Urbanos no Brasil. Rio de Janeiro: Bertrand Brasil, 2001. 418p.

DIAS, R. Turismo sustentável e meio ambiente. São Paulo: Atlas, 2009. 208p.

FREIRE DIAS, Geraldo. Educação Ambiental: princípios e práticas. São Paulo: GAIA, 6를 edição, 2000. 70p.

IGNARA, L. R. Fundamentos do turismo. 2 ed. São Paulo: Pioneira Thomson Leaerning, 2001. $205 \mathrm{p}$.

RAMOS, R. V. O. Impactos socioambientais decorrentes das atividades turísticas no município de Rio Quente (GO). Catalão: PPGGC/UFG/CAC, 2013. 


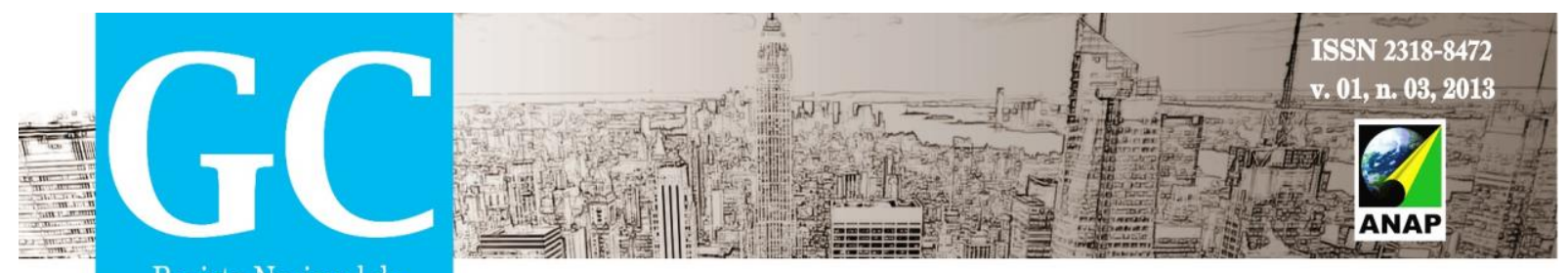

Revista Nacional de

Gerenciamento de Cidades

RUSCHMANN, D. V. de M. Turismo e planejamento sustentável: a proteção do meio ambiente. Campinas: Papirus, 1997. 167p.

SAINT-HILAIRE, A. As fabulosas águas quentes de Caldas Novas. Goiânia: Oriente, 1982. $147 p$.

TROGER, U., HAESBAERT, F. F. CAMPOS, J. E. G. Águas Quentes de Caldas Novas, Goiás. Notável ocorrência de águas termais sem associação com magmatismo. Sítios Geológicos Paleontológios do Brasil. 2005. Disponível em: <http://www.unb.br/ig/sigep/sitio113/sitio113.pdf> Acesso em 06 de jul. 2013. 